\title{
Incorporation of a Flared Inlet Capillary Tube on a Fourier Transform Ion Cyclotron Resonance Mass Spectrometer
}

\author{
Si Wu, Kai Zhang, Nathan K. Kaiser, James E. Bruce \\ Department of Chemistry, Washington State University, Pullman, Washington, USA
}

\author{
David C. Prior and Gordon A. Anderson \\ Environmental Molecular Sciences Laboratory, Pacific Northwest National Laboratory, Richland, \\ Washington, USA
}

\begin{abstract}
Flared inlet capillary tubes have been coupled with a Fourier transform ion cyclotron resonance (FT-ICR) mass spectrometer to help the ion transmission from the atmospheric pressure to the first vacuum region. We investigated different types of atmospheric pressure ionization methods using flared inlet tubes. For most of the ionization methods, such as ESI and DESI, increased ion current transmitted from the atmospheric pressure ion source to the first stage vacuum system was observed with the use of our enhanced ion inlet designs. The corresponding ion intensity detected on a FT-ICR mass spectrometer was also observed to increase two- to fivefold using ESI or DESI with the flared tube inlet. Moreover, increased spray tip positional tolerance was observed with implementation of the flared inlet tube. We also include our preliminary results obtained by coupling AP-MALDI with flared inlet tube in this paper. For AP-MALDI, the measured ion current transferred through the flared inlet tube was about 2 to 3 times larger than the ion current through the control non-flared inlet tube. (J Am Soc Mass Spectrom 2006, 17, 772-779) (C) 2006 American Society for Mass Spectrometry
\end{abstract}

A number of atmospheric pressure ionization sources, such as electrospray ionization (ESI) and atmospheric pressure matrix-assisted laser desorption/ionization (AP-MALDI), have been widely used with mass spectrometry for proteomics studies [1-5]. Desorption electrospray ionization (DESI) is an exciting new atmospheric pressure desorption ionization method introduced by Cooks et al. [6, 7]. Charged solvent droplets are sprayed directly onto an analyte surface through a pneumatically-assisted electrospray ion source. This new method is very attractive due to its utility for direct analysis of different compounds on a variety of surface types [6-8], and will enable application of mass spectrometry to more diverse, more challenging analytical problems. For all these ionization methods, the ions generated under ambient conditions are transferred through an atmospheric pressure interface such as an inlet tube or an orifice followed by several stages of differential pumping and then ions are sent to the MS detector [1-3].

A common hurdle encountered in the implementation of any atmospheric ion source is related to the

Published online April 17, 2006

Address reprint requests to Dr. J. E. Bruce, Department of Chemistry, Washington State University, P.O. Box 644630, Pullman, WA 99164-4630, USA. E-mail: james_bruce@wsu.edu transfer of ions produced at atmospheric pressure to the low vacuum mass analyzer. For all these atmospheric pressure ion sources, the gas-phase ions produced at atmospheric pressure are transferred to the lower pressure regions through conductance limits such as a metal capillary or an orifice [9, 10]. For electrospray ionization, it has been reported that gas-phase collisions and charge-charge repulsion after ion formation lead to an expansion of the ion cloud [3,11]. In AP-MALDI and DESI, ions are also dispersed once created at atmospheric pressure. Since ions must enter the MS through a small aperture or capillary with limited cross section, the ion cloud expansion and dispersion can significantly decrease the ion transmission to the lower pressure region, and thus decrease the sensitivity of the analysis. It has also been reported that the ion transmission efficiency between the ESI emitter and the inlet of the mass spectrometer is only $0.01-0.1 \%[3,12,13]$. For AP-MALDI, even with precise aperture alignment and source positioning, sampling efficiency is generally lower than the sampling efficiency in ESI [14]. Several approaches have been developed to improve ion transmission efficiencies between the ion source and the mass spectrometer as outlined below.

Smith et al. [9, 15-17] have developed an electrodynamic ion funnel interface for electrospray ionization mass spectrometry, which applies rf and dc electric 
fields to a series of ring electrodes with successively smaller i.d. apertures. The ion funnel can be situated immediately after the atmospheric pressure interface of the MS. The use of the ion funnel leads to more effective ion transmission to the analyzer region. This development has been reported to increase ion transmission efficiencies up to 23-fold. However, as the pressure in the ion funnel region increases, the required rf peak-topeak potential for efficient ion focusing increases correspondingly [9]. Due to this, the ion funnel has not achieved widespread implementation in the atmospheric pressure region between the electrospray tip and ion sampling interface, where most ion losses may occur [3].

A new dynamic focusing technique called pulsed dynamic focusing (PDF) has been developed and applied to the AP-MALDI ion source to improve ion transmission into a mass spectrometer [14, 18]. Other atmospheric pressure electrostatic lenses that improve ion transmission efficiencies in the high-pressure region have also been reported [19-21]. However, these conventional ion optic devices are not very effective in avoiding or reversing ion-cloud expansion generated by gas-phase collisions and Coulombic repulsion in high-pressure regions.

Other efforts to improve ion transmission efficiencies in the high-pressure region include nebulization gas to assist in desolvation. Henion et al. [22] reported an "ion spray" device in which an increase of about $30 \%$ in ion signal intensity was obtained compared to that obtained with a lower flow rate. An intersecting gas flow device developed by Covey [23] can provide an increase in sensitivity of more than a factor of 10 , and can significantly lower the background in the resulting mass spectra. Recent studies by Lee et al. [24] and Muddiman et al. [13] have shown large increases in ion abundance resultant from the implementation of a commercial air amplifier or a modified venturi device in the highpressure region. They also reported that these devices generated a concentric high-velocity converging gas flow around the electrospray tip to reduce spreading of the electrospray plume and improve the conductance of ions to the sampling orifice of the MS. They reported an impressive 18-fold increase in ion abundance and a 34 -fold reduction in the detection limit. These advancements were achieved without any aperture or capillary entrance modifications, as described here, and could likely be further enhanced with the design described below.

Recently, we have developed a flared inlet capillary tube to replace the conventional straight metal capillary inlet tube, which is widely used with different kinds of mass spectrometers [25]. Glish and Danell [26] developed a new glass ion sampling device, which also included a larger i.d. inlet of the capillary. Both reports showed that a larger cross section of the capillary entrance can allow more ions to enter the MS using electrospray ionization. Similar to the Venturi device $[13,24]$, the convergence of the gas flow toward the smaller end of the capillary tube can also help reduce spreading of the ion cloud and help transfer more ions into the low-pressure region. We observed that ion current from ESI could be improved by nearly a factor of three with flared inlet tubes compared with nonflared control tubes. Ion signal measured by a TOF spectrometer was similarly improved. Building on the initial report [25], we incorporated the flared inlet tube in a 7T FT-ICR-MS instrument for a more comprehensive study on ion transmission efficiency under different kinds of atmospheric pressure ionization methods such as ESI, DESI, and AP-MALDI. Improved ion transmission by coupling the flared inlet tube with different ionization methods was demonstrated by the increase in both the observed ion abundances in the FT-ICR mass spectra and the ion current measured beyond the capillary exit. Also, we observed a weaker dependence on ESI spray position relative to the capillary central axis. The results with ESI-FT-ICR-MS and DESI-FT-ICR-MS, and our initial data illustrating the benefits of coupling an AP-MALDI ion source with flared inlet tubes are reported here.

\section{Experimental}

\section{Chemicals}

Substance P and angiotensin II were purchased from Sigma (St. Louis, MO) and used without further purification. Each standard peptide in $10 \mathrm{mM}$ stock solutions were prepared in purified water $\left(18 \mathrm{M} \Omega^{*} \mathrm{~cm}\right)$ using a Nanopure ultra-purified water system from Barnstead Int., (Dubuque, IA). Analytical standards were prepared by dilution using 50/50 (vol/vol) methanol/ water with $0.1 \%$ acetic acid.

\section{Flared Inlet Tubes for the Atmospheric Pressure Interface}

The flared inlet tube was implemented in our FTICR-MS instrument as shown in the Figure 1. A set of prototype ion inlet tubes were produced either in-house or from Small Parts Inc. (Miami Lakes, FL) with various inlet sizes and configurations. The inlet tube was designed with a larger flared end which pointed towards the ion source to receive ions. In Figure 1, different angles of the flared tubes were made with $0.015 \mathrm{in}$. or 0.02 in. i.d. The o.d. of the unflared end was either 0.03 in. or 1/16 in. Non-flared tubes with the same i.d. and length were used for control studies to demonstrate the improvements of the flared tube. The lengths of both the flared tubes and non-flared tubes were variable from $6 \mathrm{in}$. to $10 \mathrm{in}$. Two different types of flared tubes were used in the ESI, DESI and ESSI experiments reported in this paper: one set was 0.02 in. i.d. and $1 / 16$ in. o.d. at the unflared end, and was flared 10 degrees from the center line to $\sim 3 \mathrm{~mm}$ o.d. at the larger end; the other set was 0.015 in. i.d. and 0.03 in. o.d. at the unflared end, and was flared with a 45 degree angle 


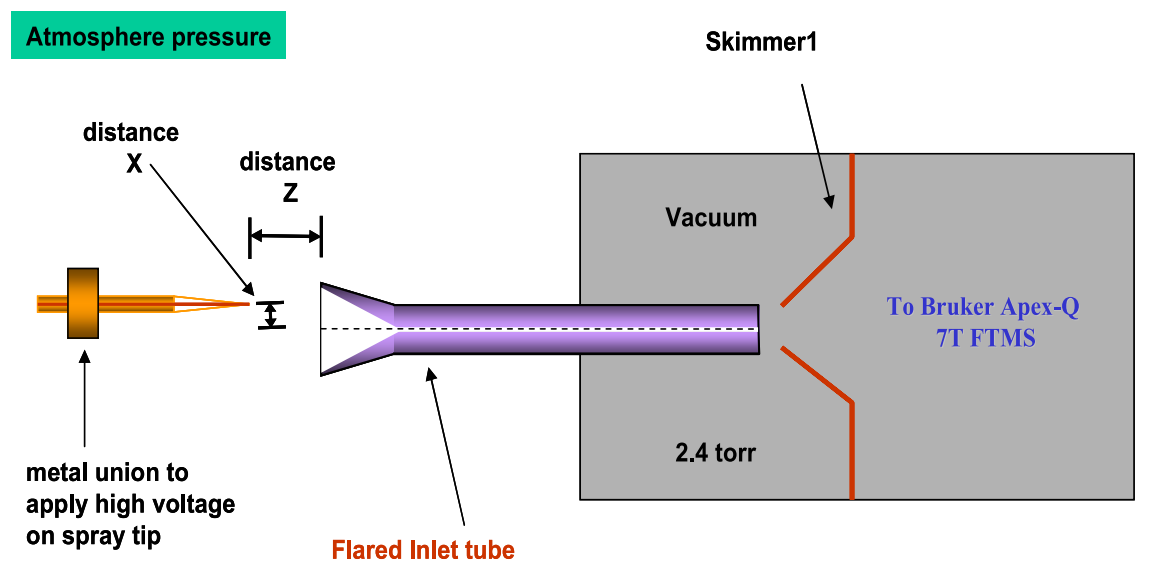

Figure 1. Schematic of the implementation of the flared inlet tube. Distance $\mathrm{Z}$ is the distance between the spray tip and the inlet interface. Distance $X$ is the distance that the spray tip is away from the inlet tube center. When the spray tip is aligned with the center of the inlet tube, Distance $X$ is 0 .

from the center line to $\sim 2.2 \mathrm{~mm}$ o.d. at the larger end. Both types of flared tubes were placed into a $1 / 4$ in stainless steel tube, which is interchangeable with the commercial glass capillary tube originally in our FTICR-MS instrument. All the capillary inlet tubes were maintained at a temperature of $220^{\circ} \mathrm{C}$ during experiments.

\section{Atmospheric Pressure Ionization Sources}

We investigated the ion transmission efficiency of flared ion inlet tubes with ESI and other atmospheric pressure ion sources such as DESI. For nanospray experiments, the spray tips were made by etching a 20 $\mu \mathrm{m}$ i.d., $360 \mu \mathrm{m}$ o.d. fused-silica capillary with $49 \% \mathrm{HF}$. Solutions of the peptides were prepared by dilution of stock solutions using $50: 50 \mathrm{MeOH}: \mathrm{H}_{2} \mathrm{O}$ with $0.1 \%$ acetic acid. Infusion was performed with a syringe pump at a flow rate of $250 \mathrm{nl} / \mathrm{min}$. A potential up to $4 \mathrm{kV}$ was applied to the sample solution through a copper alligator clip attached to the metal union before the spray tip. For ESI, the position of the spray tip was controlled by a 3D linear stage from Newport (Irvine, CA). The setup used for DESI was similar to the setup previously described by Cooks et al. [6, 7]. For DESI, a potential of 2.5 to $3.5 \mathrm{kV}$ was applied to the spray solution through a copper alligator clip attached to the stainless steel syringe tip used for sample infusion. The spray emitter was mounted about 0.5 to $1 \mathrm{~mm}$ from the sample surface at about 50 degrees (similar to the optimal conditions reported by Cooks et al. [6] and Van Berkel et al. [8]). A polytetrafluoroethylene (PTFE) surface was used in the DESI experiments and its surface area was about $20 \mathrm{~mm}^{2}$, and the position of the sample target was controlled by the 3D linear stage mentioned above. DESI solvent flow rate was about 0.5 to $1 \mu \mathrm{l} / \mathrm{min}$. Other optimal operation conditions were similar to those reported by Cooks et al. [6, 7]. We also investigated the implementation of electrosonic spray ionization method (ESSI) by comparing the flared inlet tube and the non-flared control inlet tube. The home built ESSI ion source was similar to the setup previously described ESSI ion source by Takats et al. [27]

\section{$A P-M A L D I$}

The AP-MALDI ion source described here was designed as a component of a novel high sensitivity AP-MALDI-FT-ICR mass spectrometer, which is currently under development in our laboratory. Several stages of differential pumping are incorporated in the vacuum system of this mass spectrometer. The first pumping stage (between the capillary exit and the skimmer) was evacuated by an Edwards E2M30 mechanical pump (Wilmington, MA) to 2 to 4 torr. For AP-MALDI, a pulsed nitrogen laser (model VSL337, Spectra-Physics, Irvine, CA), at a wavelength of 337.1 $\mathrm{nm}$, was employed. The laser output was attenuated using a circular variable neutral density filter, and was focused onto a small copper target plate $(\sim 2 \mathrm{~mm} \times 3$ $\mathrm{mm}$ in size) by a $10 \mathrm{~cm}$ focal length UV grade fused silica precision plano-convex lens SPX022 from Newport (Irvine, CA). Laser firing was externally triggered at a $3 \mathrm{~Hz}$ repetition rate by an arbitrary function waveform generator, model 33120A from Hewlett Packard (Palo Alto, CA). The AP-MALDI source was coupled with several types of capillary inlet tubes. The position of the sample plate relative to the interface of the inlet tube was optimized by adjustment of the 3D linear stage described above. No high voltage was applied to the sample target. We compared the ion transmission efficiency of different inlet tubes by measuring the ion current on the skimmer from each laser pulse. The generated ion current was amplified by a Keithley current amplifier Model 428 (Cleveland, OH) and then recorded by a digital storage oscilloscope model TDS 2024 from Tektronix (Richardson, TX). Samples for AP-MALDI were prepared on the sample target by mixing $2 \mu \mathrm{l} 100 \mu \mathrm{M}$ Substance P with $2 \mu \mathrm{l}$ matrix 


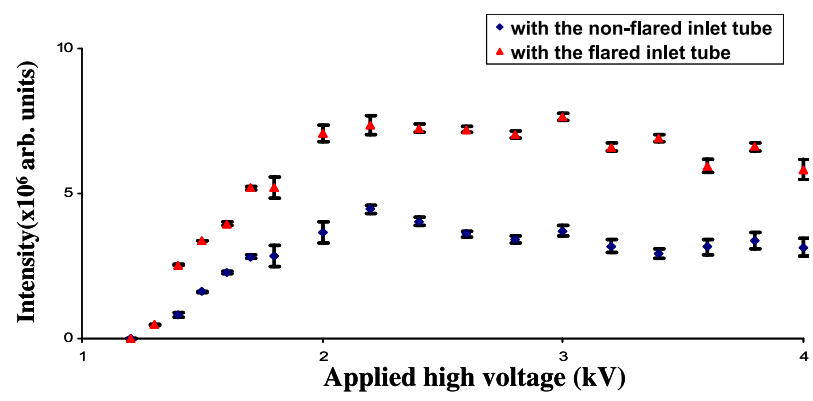

Figure 2. Total ion intensity of Substance $P$ as a function of spray potential. A $10 \mu \mathrm{M}$ Substance P solution was prepared in 50:50 $\mathrm{MeOH}: \mathrm{H}_{2} \mathrm{O}$ with $0.1 \%$ acetic acid. Infusion was performed using a syringe pump with a flow rate of $250 \mathrm{nl} / \mathrm{min}$.

solution (saturated 2,5-dihydroxybenzoic acid in 50:50: 0.1 of acetonitrile: $\mathrm{H}_{2} \mathrm{O}: \mathrm{TFA}$ ).

\section{Instrumentation}

A Bruker Daltonics (Billerica, MA) Apex-Q 7T FT-ICR mass spectrometer was used to acquire the mass spectral data. The ions entered the instrument through the flared inlet tube, and then passed through a hexapole followed by a mass-selective quadrupole and then a second hexapole. After accumulation in the second set of hexapole rods for the duration of 0.5-2 s, the ions were then sent toward the ICR cell using an electrostatic ion guide. The ions were trapped in the ICR cell using a low-energy sidekick potential [28] to keep the ions close to the central $z$ axis of the cell. All datasets acquired were $128 \mathrm{k}$ points. The mass spectral data were acquired using Xmass 7.0.6 as the data acquisition software program. The external calibration was done using a mixture solution of standard peptides. All the FT-ICR-MS data were analyzed using ICR-2LS software package [29].

\section{Results and Discussion}

\section{Electrospray Ionization}

Ion intensity comparison. As shown in the patent by Prior et al. [25], measured ion current can be increased 3 -fold or more using the flared inlet tube. The original data compared the ion signal from the magnetic-bottle time of flight photoelectron spectrometer using ESI with flared inlet tube or with non-flared control tube. Here we applied the flared inlet tube on our FT-ICR-MS instrument with a variety of ion sources. We evaluated total ion signal intensity for each mass spectrum. We also measured the ion current transmitted through the capillary tube by placing an aluminum plate $\sim 3 \mathrm{~mm}$ beyond the capillary exit. Figure 2 shows the total ion intensity measurements as a function of spray potential with or without the flared inlet tube. The flared inlet tube used for this research was $0.015 \mathrm{in.}$ i.d. and $0.03 \mathrm{in.}$ o.d. at the unflared end, and was flared with a 45 degree angle from the center line to $\sim 2.2 \mathrm{~mm}$ o.d. at the larger end. A $10 \mu \mathrm{M}$ Substance P solution was used for both sets of experiments, and the MS operating parameters and infusion rates were held constant. The distance between the spray tip and the capillary was $1 \mathrm{~mm}$ for both cases, and the tip was aligned to the capillary center with careful adjustments. With ESI, the ion signal intensity is generally dependent on the high voltage applied to the spray tip. Most of the time, the ion signal will be initiated at some minimum voltage and will increase with increasing voltage until the signal intensity reaches some maximum value [3]. Figure 2 shows that this maximum ion intensity value was achieved at the spray potential of $2.2 \mathrm{kV}$ with or without the flared inlet tube. However, we observed nearly a 2 -fold increase in ion intensity with the implementation of the flared inlet tube. From the measurement of current via the aluminum plate beyond the exit of the capillary tube, we also observed a 3-fold increase in the ion current transmitted through the capillary. Since both ion current and measured ion signal are increased, we believe that the flared inlet tube significantly improves the ion transmission from atmospheric pressure to the first vacuum stage, and therefore improves the ion signal intensity detected with the mass spectrometer. These improvements are likely related to the convergence of the gas flow and larger angle of acceptance of the flared tubes compared with the conventional ion inlet tubes. When using the non-flared inlet tube, only a small portion of the ions in the plume can be transferred due to the small i.d. of the inlet tube. With the flared inlet tube, the much larger entrance and acceptance angle can help to transfer a much larger portion of the ions in the plume. However, since the ion plume diffusion due to Coulombic repulsion may not be as significant for low concentration samples as for the samples studied here, smaller improvements in ion transmission may be observed for lower concentration samples.

Dependence of tip position. The location of the spray tip relative to the capillary central axis is very critical to

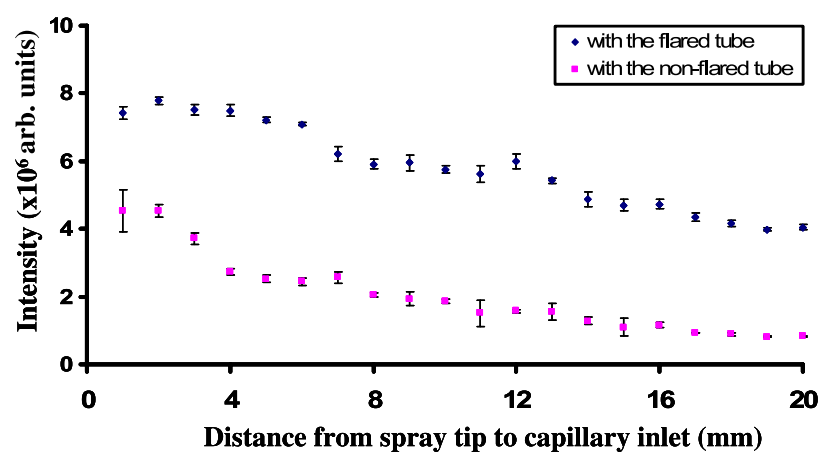

Figure 3. Total ion intensity of Substance $P$ as a function of the distance between spray tip and inlet interface (Distance Z). A 10 $\mu \mathrm{M}$ Substance $\mathrm{P}$ solution was prepared in $50: 50 \mathrm{MeOH}: \mathrm{H}_{2} \mathrm{O}$ with $0.1 \%$ acetic acid. Infusion was performed using a syringe pump with a flow rate of $250 \mathrm{nl} / \mathrm{min}$. 
achieve the optimum ion transmission when using a non-flared control capillary inlet tube. To determine the dependence of the tip position relative to the capillary central axis with the flared inlet tube, we did a series of experiments where the distance between the spray tip and inlet interface (Distance $\mathrm{Z}$ in Figure 1) was varied, or the distance that the spray tip is away from the inlet tube center (Distance $X$ in Figure 1) was varied. The flared tube used in these experiments was 0.015 in i.d. and 0.03 in o.d. at the smaller end with a flared 45 degree angle at the larger end from the center line to $\sim 2.2 \mathrm{~mm}$ i.d. (the distance from the center to the edge was about $1.1 \mathrm{~mm}$ ).

Direct infusion of $10 \mu \mathrm{M}$ Substance P solution was used for the determination of spray tip position effects on signal intensities. As mentioned above, we evaluated the total ion intensity for each spectrum. Figure 3 shows the total ion intensity of Substance P ions from the FT-ICR-MS as a function of the distance between the spray tip and inlet surface (Distance Z). As shown in Figure 3, when we moved the spray tip further from the inlet interface, the ion intensity started to decrease at about $2 \mathrm{~mm}$ with the flared inlet tube or with the non-flared control tube. However, the initial rate of decrease of ion intensity with the non-flared ion inlet tube was found to be much higher than that observed with the flared ion inlet tube. Ion signal intensity decreased by $50 \%$ within the Distance Z of $5 \mathrm{~mm}$ when using the non-flared tube. For the flared tube, the ion signal intensity decreased much slower. This may result from the fact that a larger electrospray plume due to charge-charge repulsion is present with ESI at longer tip-to-entrance distances. With the use of the flared tube, the convergence of the gas flow toward the smaller end of the capillary tube can help to reduce the spreading of the ion cloud, resulting in a smaller decrease in the ion intensity.

Figure 4 demonstrates the observed change in the total ion intensity of Substance P ions observed when the relative position of the spray tip and the inlet center (Distance X) was varied. A spray potential of $3 \mathrm{kV}$ was applied for both cases, which was optimal for both the flared capillary tube and the non-flared capillary tube. With a constant distance $\mathrm{Z}$ of $1 \mathrm{~mm}$ with the non-flared tube, we found that the ion intensity decreased quickly with increasing Distance $X$ and ion signal was completely gone when Distance $X$ was $0.8 \mathrm{~mm}$. However, when we employed the flared tube (Distance $Z=1$ $\mathrm{mm}$ ), the ion intensity measured by FT-ICR-MS was observed to be constant without significant decrease when the Distance $X$ was increased as large as $1.2 \mathrm{~mm}$. When we increased the Distance $X$ greater than $1.2 \mathrm{~mm}$, ion signal started to decrease and the signal-to-noise ratio of the peak approached 1 at the Distance $X$ of 2.0 $\mathrm{mm}$. Since the diameter of the flared inlet interface is about $2.2 \mathrm{~mm}$, when we moved the spray tip to the Distance $X$ of $1.2 \mathrm{~mm}$, the tip position is near the outer edge of the flared inlet interface. These results showed that we can observe constant ion signal when we keep
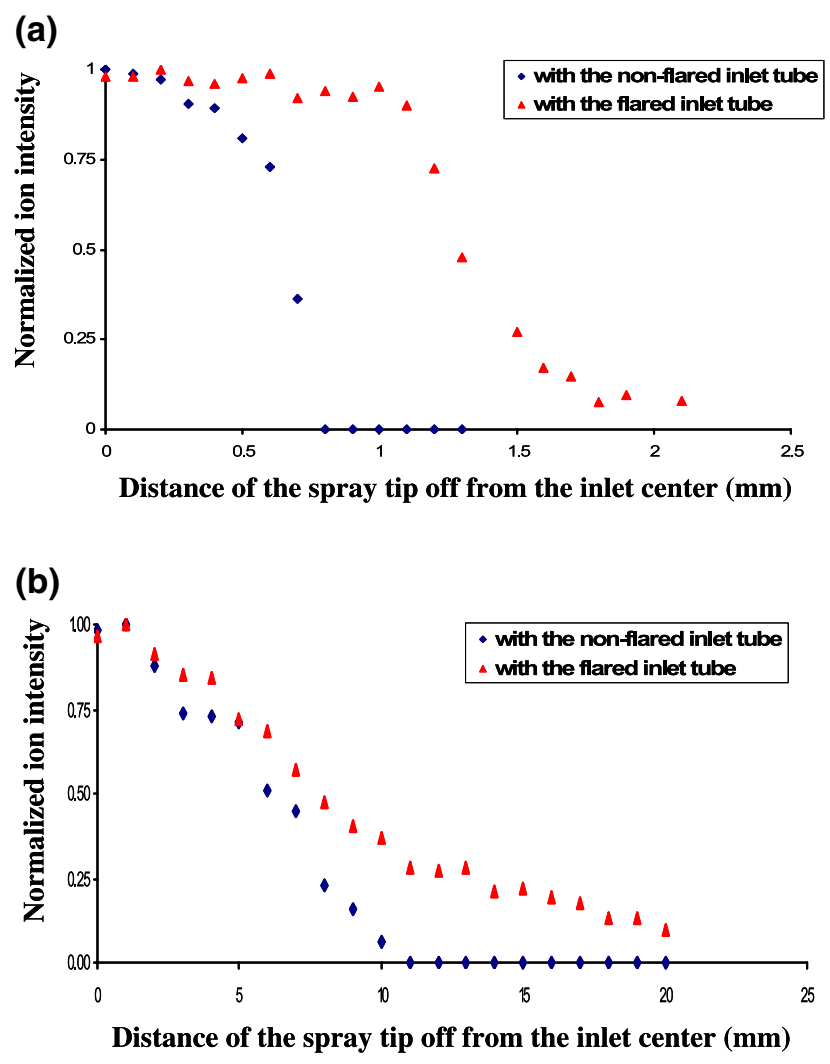

Figure 4. Normalized total ion intensity of Substance $P$ as a function of the distance that the spray tip was away from the inlet tube center (Distance X). Ion intensities were normalized individually using the most intense peak with or without flared inlet tube. A $10 \mu \mathrm{M}$ Substance P solution was infused at a flow rate of 250 $\mathrm{nl} / \mathrm{min}$. (a) The distance between spray tip and inlet interface (Distance $\mathrm{Z}$ ) is $1 \mathrm{~mm}$. (b) The distance between spray tip and inlet interface (Distance $Z$ ) is $10 \mathrm{~mm}$.

the spray tip in any position inside the interface area (Distance $Z=1 \mathrm{~mm}$ ). Similar results were also observed when we increased the Distance $Z$ to $10 \mathrm{~mm}$ (Figure $4 \mathrm{~b}$ ). As mentioned above, with the longer Distance $Z$, the larger ion plume of ESI spray can be formed due to the longer time for charge-charge repulsion to result in ion dispersion before capillary entrance. Thus, the longer distance leads the smaller portion of ions transferred through the capillary tube. However, the larger ion plume results in less dependence on the spray tip position relative to the inlet center. Therefore, we expect the ion signal to decrease slower by increasing the Distance $X$ using longer Distance Z. As shown in Figure $4 \mathrm{~b}$, even with the non-flared inlet tube, ion signal was observed when the Distance $X$ was smaller than $10 \mathrm{~mm}$. However, with the flared inlet tube, this distance increased to $20 \mathrm{~mm}$. Therefore, ion signal was observed to be less dependent on the spray tip position with the use of the flared inlet tube. Overall, the increase of the spray tip positional tolerance observed with the flared inlet tube can significantly increase sensitivity and reduce the efforts required to optimize spray performance, compared with a non-flared control inlet tube. 
(a)
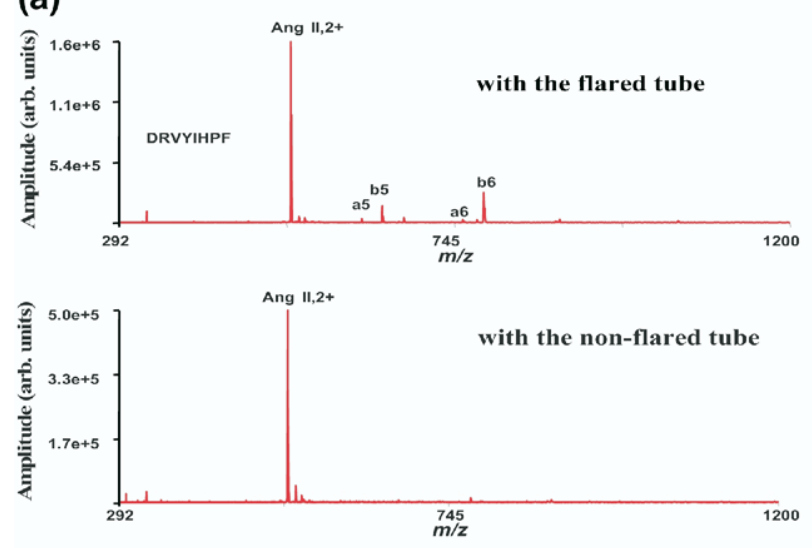

(b)

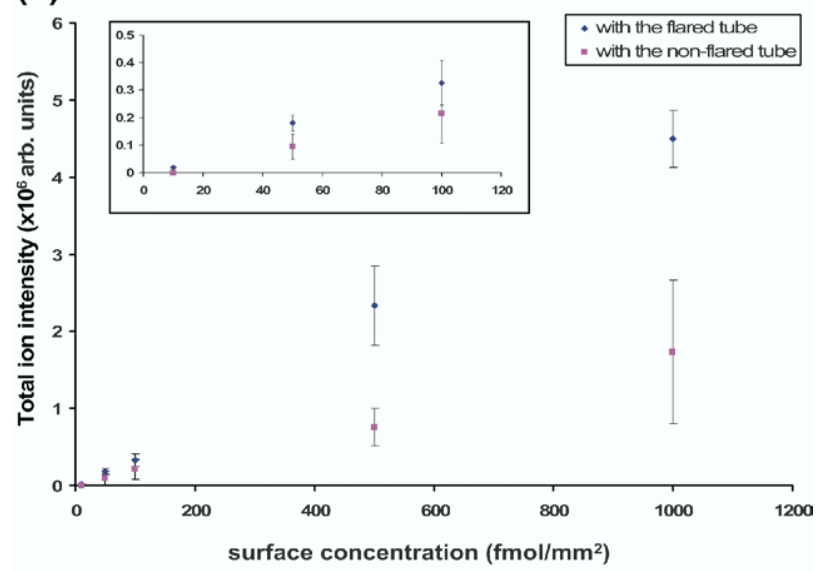

Figure 5. DESI of angiotensin II on the PTFE surface. (a) DESI spectra with the highest ion intensity among 300 spectra with the flared inlet tube or with the non-flared control inlet tube. The average surface concentration of angiotensin II was $500 \mathrm{fmol} /$ $\mathrm{mm}^{2}$. Each spectrum was accumulated 0.5 seconds and a total of 300 spectra were collected for one spot. (b) Plot of mass spectral total ion intensity versus the amount of angiotensin II spotted on the same sample holder with disposable surface. The average of 10 highest intensities achieved from each spot was compared. Triplicate experiments were performed for each sample concentration. Inset illustrates the data in the low concentration region.

\section{Desorption Electrospray Ionization (DESI) and Electrosonic Spray Ionization (ESSI)}

A series of angiotensin II solutions with various analyte concentration values were analyzed with flared and non-flared inlet tubes to determine if the flared inlet tube can improve the ion transmission efficiency using DESI. Five different solutions of angiotensin II were used for sampling on a PTFE surface with an average surface sample concentration of 10, 50, 100, 500, and $1000 \mathrm{fmol} / \mathrm{mm}^{2}$ (we adopted the average surface concentration concept as published by Cooks et al. [6]). For each spot, a series of scans with 1s ion accumulation time was acquired. As shown in Figure 5a, for a 500 $\mathrm{fmol} / \mathrm{mm}^{2}$ sample, the highest ion intensity among all the scans collected for a single spot using the non-flared tube is about 3 to 4 times less than the highest ion intensity using flared tube. For each spot, the average of 10 highest total ion intensities was plotted as a function of sample concentration, as shown in Figure $5 \mathrm{~b}$. The error bars in Figure 5b represent the standard deviation resultant from three independent spot analyses. To demonstrate the improvements using the flared inlet tube, we calculated the average intensity ratio of the flared inlet tube to the non-flared control inlet tube at each concentration. While comparing with the standard inlet tube, we found an overall 2.5-fold increase in the average ion intensity with use of the flared tube with DESI. In addition, the lowest surface sample concentration that produced measurable ion signals with DESIFT-ICR-MS was $50 \mathrm{fmol} / \mathrm{mm}^{2}$ with the use of the non-flared inlet tube. However, the lowest surface sample concentration observable with DESI decreased to 10 $\mathrm{fmol} / \mathrm{mm}^{2}$ with the use of the flared tube. These results show a factor of 2.5 to 5 improvement in both $\mathrm{S} / \mathrm{N}$ and limit of detection (LOD) with the use of the flared inlet tube with DESI. As with the studies of coupling ESI and the flared inlet tubes described above, we also found that the sample target positional tolerance relative to the capillary tube was increased with the implementation of the flared inlet (data not shown here).

We have also evaluated the measured ion current and the corresponding ion intensity for mass spectra acquired with the flared inlet tube and with the nonflared control inlet tube using ESSI [27]. However, no significant improvement of total ion signal was observed with the flared inlet tube (data not shown here) when we aligned the tip very carefully to the capillary center. This was different from ESI and DESI results described above, and may result from the greater overall charge and repulsion of ions with ESI that leads to greater radial dispersion of ions compared with ESSI $[27,30]$.

\section{Coupling the Flared Inlet Tube with AP-MALDI}

To investigate the effects of the flared inlet tube on the transmission of ions produced by AP-MALDI, we used an inlet tube which was 0.03 in. i.d. and 1/16 in. o.d. at the unflared end, 9.3 in total length, and was flared 30 degrees from the center line to $\sim 3 \mathrm{~mm}$ o.d. at the larger end. The corresponding control non-flared inlet tube we used was 0.03 in. i.d. and $1 / 16$ in. o.d. with a total length of $10 \mathrm{in}$. The choice of larger diameter inlet tube here was made to allow us to record and compare the ion current from AP-MALDI ion source. In general, the ion current generated by AP-MALDI was much smaller that the ion current generated by ESI [14] and with smaller i.d. capillaries, became difficult to measure. We recorded output of the current amplifier with a digital oscilloscope and synchronized the scope to the laser firing by triggering the oscilloscope using the same triggering signal from the functional waveform generator which was used to fire the laser pulse. The ion current for each sample spot was measured on the skimmer and was recorded by averaging 16 scans of 


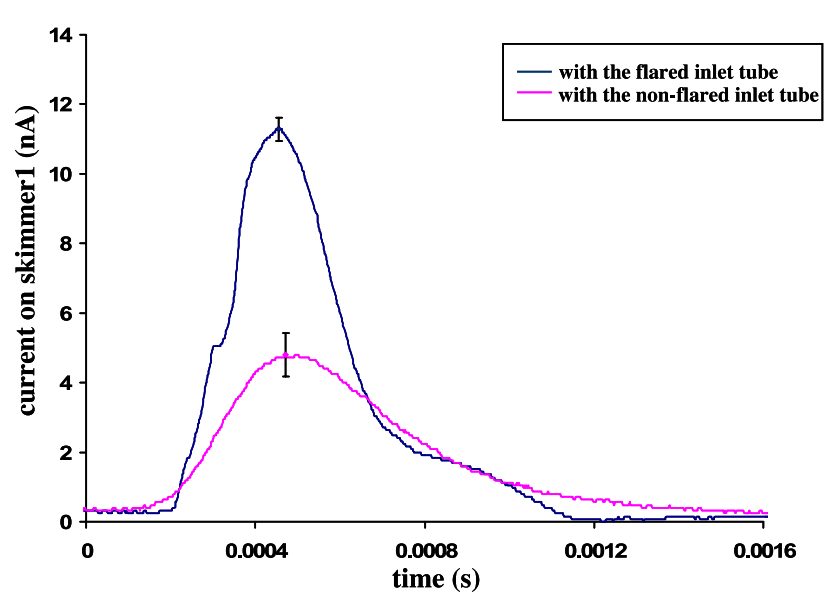

Figure 6. Average ion current profiling on the skimmer1 using AP-MALDI ion source. Each plot is an average of 16 laser shots on the same sample spot. The error bars represent the standard deviation of the peak measured ion current from three different sample spots.

current signals corresponding to 16 laser pulses. We found the ion current arrival time at the skimmer was slightly delayed for the non-flared tube compared to the flared inlet tube, which is expected because the inlet tube lengths of the flared and non-flared tubes were slightly different (9.3 in versus 10 in). However, since the overall lengths of the tubes were similar, as was the measured pressure near the capillary exit (4.0 torr versus 3.6 torr), we believed that the measured ion current values are still comparable. To demonstrate the differences observed with AP-MALDI, we overlaid the ion current profiles with the flared inlet tube and with the control tube. Figure 6 is the overlay comparison of the recorded ion current responses with the flared inlet tube and with the non-flared inlet tube. The error bars indicated on the peak values of each profile illustrate the standard deviation resultant from peak current measurements from 3 sample spots. We observed approximately a 3-fold increase in ion current measured on the skimmer with implementation of the flared inlet tube. Ion current peak width of the laser pulse with the flared tube was slightly smaller than the peak width with the control tube. The calculated average peak area with the flared tube was 2.4 times larger than the calculated average peak area with the non-flared tube. Although the ion current we measured hitting on the skimmer likely included many matrix ions other than gas-phase analyte ions, this current is anticipated to be proportional to the analyte ion signal detected by the mass spectrometer. Based on these preliminary results, in the future we will design a new AP-MALDI ion source for the Bruker 7T FT-ICR mass spectrometer and incorporate with the flared inlet tube as the atmospheric pressure interface. We expect similar improvements in the measured ion signal intensities, as we have observed with most other atmospheric ion sources.

\section{Conclusions}

A new type of atmospheric pressure interface with FT-ICR-MS was employed with a flared inlet tube. The flared inlet tube can efficiently focus ions at atmospheric pressure from a variety of ion sources, including ESI, DESI, and AP-MALDI. The application of a flared inlet tube to nano-electrospray ionization resulted in a 2-fold increase of the measured ion intensity. Also, our studies on the tip position relative to the inlet tube showed relative tip-inlet position adjustment was less critical for optimal performance with the flared tubes, compared with conventional non-flared inlet tubes. With the application of the flared inlet tube to DESI, we also observed a significant increase in the measured ion intensity. The lowest surface sample concentration that can be successfully detected with DESI on our instrument also decreased to $10 \mathrm{fmol} /$ $\mathrm{mm}^{2}$, a 5-fold improvement in LOD with the use of the flared inlet tube. Our preliminary studies with an AP-MALDI ion source with the flared inlet tube demonstrated that more ions can be transferred through the flared inlet tube. In future work, we will implement the AP-MALDI ion source with our 7T FT-ICR-MS by coupling with the flared inlet tube.

In addition to greater ion current, another advantage of the flared inlet tube is that standard capillary tubes can be easily replaced with flared inlet tubes without additional significant instrument modifications. This makes the flared inlet tube very attractive, since it is readily combined with other atmospheric pressure or high-pressure ion focusing techniques. For example, a possible combination is to incorporate the Venturi device described by Lee et al. [24] and Muddiman et al. [13] with the flared inlet tube. Coupling with the flared inlet tube can potentially further improve the performance of the Venturi device due to the larger cross section area of the flared tube. Another area where the flared inlet tube will likely significantly benefit analysis is in the coupling of atmospheric pressure gas-phase separation techniques like IMS [31] or FAIMS [32, 33]. Robinson and Williams [34] have demonstrated significant decrease in background chemical noise possible with FAIMS-FTICR-MS coupling that significantly enhances dynamic range. These efforts can likely be even further improved with methods that allow more efficient transmission of ions from atmospheric pressure to the first stage of the vacuum system, as is possible with the flared inlet. Finally, the combination of the flared inlet with the ion funnel introduced by Smith et al. [15], and adopted in other groups as well [35], is also likely to produce greater sensitivity since these devices show significant improvement in ion focusing in the vacuum stage after the capillary tube. By combining the flared inlet tube with the ion funnel, we anticipate that more ions can be transferred to the detector, and even greater sensitivity can be achieved. 


\section{Acknowledgments}

This work was supported by grants from the M. J. Murdock Charitable Trust; the Directorate of Biological Sciences, National Science Foundation, grant no. DBI-0352451; and the Office of Science (BER), U.S. Department of Energy, grant no. DE-FG0204ER63924. The authors are also grateful to PNNL for providing the software ICR-2LS used for data analysis.

\section{References}

1. Fenn, J. B.; Mann, M.; Meng, C. K.; Wong, S. F.; Whitehouse, C. M. Electrospray Ionization for Mass Spectrometry of Large Biomolecules. Science 1989, 246, 64-71.

2. Whitehouse, C. M.; Dreyer, R. N.; Yamashita, M.; Fenn, J. B. Electrospray Interface for Liquid Chromatographs and Mass Spectrometers. Anal. Chem. 1985, 57, 675-679.

3. Cech, N. B.; Enke, C. G. Practical Implications of Some Recent Studies in Electrospray Ionization Fundamentals. Mass Spectrom Rev. 2001, 20, 362-387.

4. Laiko, V. V.; Baldwin, M. A.; Burlingame, A. L. Atmospheric Pressure Matrix-Assisted Laser Desorption/Ionization Mass Spectrometry. Anal. Chem. 2000, 72, 652-657.

5. Laiko, V. V.; Moyer, S. C.; Cotter, R. J. Atmospheric Pressure MALDI/ Ion Trap Mass Spectrometry. Anal. Chem. 2000, 72, 5239-5243.

6. Takats, Z.; Wiseman, J. M.; Gologan, B.; Cooks, R. G. Mass Spectrometry Sampling Under Ambient Conditions with Desorption Electrospray Ionization. Science 2004, 306, 471-473.

7. Takats,Z.; Cotte-Rodriguez, I.; Talaty, N.; Chen, H.; Cooks, R. G. Direct, Trace Level Detection of Explosives on Ambient Surfaces by Desorption Electrospray Ionization Mass Spectrometry. Chem. Commun. (Camb) 2005, 17, 1950-1952.

8. Van Berkel, G. J.; Ford, M. J.; Deibel, M. A. Thin-Layer Chromatography and Mass Spectrometry Coupled Using Desorption Electrospray Ionization. Anal. Chem. 2005, 77, 1207-1215.

9. Shaffer, S. A.; Tolmachev, A.; Prior, D. C.; Anderson, G. A.; Udseth, H. R.; Smith, R. D. Characterization of an Improved Electrodynamic Ion Funnel Interface for Electrospray Ionization Mass Spectrometry. Anal. Chem. 1999, 71, 2957-2964.

10. Burlingame, A. L.; Boyd, R. K.; Gaskell, S. J. Mass Spectrometry. Anal. Chem. 1998, 70, 647R-716R.

11. Dodonov, A.; Kozlovsky, V.; Loboda, A.; Raznikov, V.; Sulimenkov, I.; Tolmachev, A.; Kraft, A.; Wollnik, H. A New Technique for Decomposition of Selected Ions in Molecule Ion Reactor Coupled with OrthoTime-of-Flight Mass Spectrometry. Rapid Commun. Mass Spectrom. 1997, 11, 1649-1656.

12. Mann, M.1990; Hedin, A.; Sundqvist, B.; Benninghoven, A., Eds.; In Ion Formation from Organic Solids V; pp 139-144.John Willey and Sons: New York, NY

13. Hawkridge, A. M.; Zhou, L.; Lee, M. L.; Muddiman, D. C. Analytical Performance of a Venturi Device Integrated into an Electrospray Ionization Fourier Transform Ion Cyclotron Resonance Mass Spectrometer for Analysis of Nucleic Acids. Anal. Chem. 2004, 76, 4118-4122.

14. Kellersberger, K. A.; Tan, P. V.; Laiko, V. V.; Doroshenko, V. M.; Fabris, D. Atmospheric Pressure MALDI-Fourier Transform Mass Spectrometry. Anal. Chem. 2004, 76, 3930-3934.

15. Shaffer, S. A.; Prior, D. C.; Anderson, G. A.; Udseth, H. R.; Smith, R. D. An Ion Funnel Interface for Improved Ion Focusing and Sensitivity
Using Electrospray Ionization Mass Spectrometry. Anal. Chem. 1998, 70, 4111-4119.

16. Belov, M. E.; Gorshkov, M. V.; Udseth, H. R.; Anderson, G. A.; Smith, R. D. Zeptomole-Sensitivity Electrospray Ionization-Fourier Transform Ion Cyclotron Resonance Mass Spectrometry of Proteins. Anal. Chem. 2000, 72, 2271-2279.

17. Belov, M. E.; Gorshkov, M. V.; Udseth, H. R.; Anderson, G. A.; Tolmachev, A. V.; Prior, D. C.; Harkewicz, R.; Smith, R. D. Initial Implementation of an Electrodynamic Ion Funnel with Fourier Transform Ion Cyclotron Resonance Mass Spectrometry. J. Am. Soc. Mass Spectrom 2000, 11, 19-23.

18. Tan, P. V.; Laiko, V. V.; Doroshenko, V. M. Atmospheric Pressure MALDI with Pulsed Dynamic Focusing for High-Efficiency Transmission of Ions into a Mass Spectrometer. Anal. Chem. 2004, 76, 2462-2469.

19. Schneider, B. B.; Douglas, D. J.; Chen, D. D. Multiple Sprayer System for High-Throughput Electrospray Ionization Mass Spectrometry. Rapid Commun. Mass Spectrom 2002, 16, 1982-1990.

20. Schneider, B. B.; Douglas, D. J.; Chen, D. D. An Atmospheric Pressure Ion Lens That Improves Nebulizer Assisted Electrospray Ion Sources. J. Am. Soc. Mass Spectrom 2002, 13, 906-913.

21. Feng, X.; Agnes, G. R. Single Isolated Droplets with Net Charge as a Source of Ions. J. Am. Soc. Mass Spectrom 2000, 11, 393-399.

22. Henion, J. D., Covey, T. R., Bruins, A. P. U.S. Patent 4,861,988; 1989.

23. Covey, T. R. U.S. Patent 5,412,208; 1995.

24. Zhou, L.; Yue, B.; Dearden, D. V.; Lee, E. D.; Rockwood, A. L.; Lee, M. L. Incorporation of a Venturi Device in Electrospray Ionization. Anal. Chem. 2003, 75, 5978-5983.

25. Prior, D. C., Price, J., Bruce, J. E. U.S. Patent 6,455,846; 2002.

26. Glish, G. L., Danell, R. M. U.S. Patent 6,703,611; 2004.

27. Takats, Z.; Wiseman, J. M.; Gologan, B.; Cooks, R. G. Electrosonic Spray Ionization. A Gentle Technique for Generating Folded Proteins and Protein Complexes in the Gas Phase and for Studying Ion-Molecule Reactions at Atmospheric Pressure. Anal. Chem. 2004, 76, 4050-4058.

28. Polfer, N. C.; Haselmann, K. F.; Zubarev, R. A.; Langridge-Smith, P. R. Electron Capture Dissociation of Polypeptides Using a 3 Tesla Fourier Transform Ion Cyclotron Resonance Mass Spectrometer. Rapid Commun. Mass Spectrom 2002, 16, 936-943.

29. Anderson, G. A., Bruce, J. E., Smith, R. D. ICR-2LS, Version 2.18 ed.; Pacific Northwest National Laboratory: Richmond, WA, 1996.

30. Hirabayashi, A. A Novel Nanoflow Interface for Atmospheric Pressure Ionization Mass Spectrometry. Rapid Commun. Mass Spectrom. 2003, 17, 391-394.

31. Hill, H. H., Jr.; Siems, W. F.; St. Louis, R. H.; McMinn, D. G. Ion Mobility Spectrometry. Anal. Chem. 1990, 62, 1201A-1209A.

32. Guevremont, R.; Ding, L.; Ells, B.; Barnett, D. A.; Purves, R. W. Atmospheric Pressure Ion Trapping in a Tandem FAIMS-FAIMS Coupled to a TOFMS: Studies with Electrospray Generated Gramicidin S Ions. J. Am. Soc. Mass Spectrom 2001, 12, 1320-1330.

33. Purves, R. W. Barnett, D. A.; Ells, B.; Guevremont, R. Gas-Phase Conformers of the $[\mathrm{M}+2 \mathrm{~h}](2+)$ Ion of Bradykinin Investigated by Combining High-Field Asymmetric Waveform Ion Mobility Spectrometry, Hydrogen/Deuterium Exchange, and Energy-Loss Measurements. Rapid Commun. Mass Spectrom 2001, 15, 1453-1456.

34. Robinson, E. W.; Williams, E. R. Multidimensional Separations of Ubiquitin Conformers in the Gas Phase: Relating Ion Cross Sections to H/D Exchange Measurements. J. Am. Soc. Mass Spectrom. 2005, 16, 1427-1437.

35. Julian, R. R.; Mabbett, S. R.; Jarrold, M. F. Ion Funnels for the Masses: Experiments and Simulations with a Simplified Ion Funnel. J. Am. Soc. Mass Spectrom 2005, 16, 1708-1712. 